\title{
Crescimento e produção de tomate cereja em sistema hidropônico com rejeito de dessalinização ${ }^{1}$
}

\author{
Cherry tomato growth and yield in soilless system using wastewater from \\ desalination process
}

\author{
Jonath Werissimo da Silva Gomes ${ }^{2}$, Nildo da Silva Dias ${ }^{3 *}$, André Moreira de Oliveira ${ }^{4}$, Flávio Favaro Blanco e $^{5}$ \\ Osvaldo Nogueira de Sousa Neto ${ }^{4}$
}

\begin{abstract}
Resumo - A produtividade agrícola sustentável é o maior desafio nas regiões áridas e semiáridas por causa da escassez de água para irrigação, sendo comum o uso de água salobra para irrigação. O objetivo desta pesquisa foi avaliar a resposta do tomate cereja (Lycopersicon esculentum L., cv. Samambaia) sob quatro níveis de salinidade da solução nutritiva com adição de rejeito salino em sistema de produção hidropônico. As plantas de tomate foram cultivadas em vasos com substrato de fibra de coco e irrigadas com soluções nutritivas preparadas com água de abastecimento e com águas salinas preparadas diluindo-se água de rejeito coletado em um dessalinizador a $75 \% ; 50 \%$ e $25 \%$ e $0 \%$, correspondendo à condutividades elétricas de 2,$1 ; 3,55 ; 4,88$, 6,02 e $6,96 \mathrm{dS} \mathrm{m}^{-1}$, respectivamente. O delineamento experimental foi inteiramente casualizado, com 5 tratamentos (níveis de salinidade da solução nutritiva) e quatro repetições. A altura e a massa seca das plantas reduziram com o aumento da salinidade da água de irrigação. O consumo hídrico da cultura foi influenciada pela adição de rejeito salino na solução nutritiva e a salinidade limiar, considerando-se a produtividade da cultura, ficou em torno de $3,51 \mathrm{dS} \mathrm{m}^{-1}$. A adição de até $25 \%$ de rejeito de dessalinizador (diluição de 75\%) à solução nutritiva permite o cultivo do tomate cereja, cv. 'Samambaia', sem haver redução na produtividade.
\end{abstract}

Palavras-chave - Lycopersicon esculentum Mill. Solução nutritiva. Salinidade. Evapotranspiração.

\begin{abstract}
Sustainable agricultural production is the most challenge facing many arid and semiarid regions due to the severe shortage of water for irrigation, thus the use of saline water for irrigation is common. The aim of this research was to examine the response of cherry tomato (Lycopersicon esculentum L., cv. Samambaia) under four levels of salinity of the nutritional solution with added water reject from desalting under soilless conditions. Plants were grown in pots filled with coconut fiber and irrigated with nutrient solutions prepared with tap water and with saline waters prepared by dilution of reject water from brine desalination at $75 ; 50 ; 25$ and $0 \%$ (CE of $2.1 ; 3.55 ; 4.88 ; 6.02$ and $6.96 \mathrm{dS} \mathrm{m}^{-1}$, respectively). A completely randomized design was used with four replications and 5 treatments (salinity levels of the nutrient solutions). The hídrico consumption of the culture was influenced by the addition of rejects saline in the nutritional solution and the salinity threshold, considering itself it productivity of the culture, was around $3,51 \mathrm{dS} \mathrm{m}^{-1}$ in the nutrient solution. Addition of up to $25 \%$ of reject ( $75 \%$ dilution) to nutrient solution allow cropping cherry tomato, cv. 'Samambaia', without any yield reduction.
\end{abstract}

Keywords - Lycopersicon esculentum L. nutrient solution. electric conductivity.

\footnotetext{
* Autor para correspondência

'Recebido para publicação em 31/08/2010; aprovado em 31/01/2011

Trabalho submetido e selecionado no primeiro Simpósio Brasileiro de Salinidade realizado de 12-15/10/2010 em Fortaleza, Ceará, Brasil

${ }^{2}$ Departamento de Ciências Ambientais e Tecnológica/UFERSA, Caixa Postal 137, Mossoró-RN, Brasil, 59.625900

${ }^{3}$ Departamento. de Ciências Ambientais e Tecnológica, Universidade Federal Rural do Semi-Árido, Mossoró-RN, Brasil, (0XX84) 3315.17416, nildo@ ufersa.edu.br

${ }^{4}$ Departamento de Ciências Ambientais e Tecnológica/UFERSA, Mossoró-RN, Brasil

${ }^{5}$ Pesquisador, Embrapa Meio-Norte, Teresina-PI, Brasil
} 


\section{Introdução}

Em todo o mundo, em razão da crescente demanda por água, cada vez mais se testemunha a utilização de águas caracterizadas como de qualidade inferior, sendo essas: efluentes de sistemas de drenagens urbana e rural, esgoto, águas salobras e rejeito de dessalinizadores. No ambiente semiárido brasileiro, devido à escassez de águas superficiais, o grande desafio é promover o abastecimento de água às famílias rurais e garantir a produção de alimentos. $\mathrm{O}$ uso de águas subterrâneas é uma alternativa viável para garantir o acesso dessas comunidades à água, a partir de investimentos públicos na perfuração de poços tubulares. Entretanto, essas fontes hídricas apresentam na maioria dos casos restrições de uso para o consumo humano (AYERS; WESTCOT, 1999), por apresentarem problemas de salinidade.

Para suprir a necessidade por águas de boa qualidade das comunidades rurais de Mossoró-RN, as quais são abastecidas com água proveniente do aquífero Jandaíra, que há concentração elevada de sais; tem-se utilizado equipamentos dessalinizadores, capazes de reduzirem a níveis muito baixos de sais as águas captadas destes poços subsuperficiais, viabilizando sua utilização para o consumo humano. A tecnologia amplamente utilizada tem sido a dessalinização por osmose reversa e, essa técnica tem um fator limitante que é a produção de um rejeito de água com alta salinidade, o qual necessita ser utilizado de forma ambientalmente correta, possibilitando, sempre que possível, a produção de alimentos.

No Brasil, o rejeito da dessalinização não está recebendo, na quase totalidade dos casos, qualquer tratamento; mesmo assim, está sendo despejado no solo, propiciando alto acúmulo de sais nas camadas superficiais do terreno (PORTO et al., 2001). Riley et al. (1997) consideraram o cultivo de plantas halófitas a melhor opção para dispor o rejeito da osmose reversa; já para Soares et al. (2006) afirmam que o uso do rejeito para irrigação de plantas halófitas forrageiras pode ser incompatível com a seguridade ambiental em razão da ineficiência de extração de sais dessas plantas frente ao montante aplicado ao solo.

Uma opção para dispor o rejeito da dessalinização é a sua utilização na solução nutritiva em cultivos hidropônicos de hortaliças, já que a tolerância das plantas à salinidade em sistemas hidropônicos é maior em relação ao sistema convencional, pois a inexistência do potencial mátrico sobre o potencial total da água irá reduzir a dificuldade de absorção de água pelas plantas (SOARES et al., 2006). Além disso, no sistema hidropônico o rejeito da dessalinização de água já está captado, podendo ser diluído para recirculação e irrigar outras cultura ou ainda ser facilmente direcionado para concentração em tanques de evaporação, evitando seu despejo no solo. Com isso, espera-se que os cultivos de plantas em sistema hidropônico proporcionem o uso sustentável das águas salobras provenientes da dessalinização.

Por outro lado, a exploração de culturas moderadamente sensível à salinidade (AYERS; WESTCOT, 1999), como o tomate, terá sua produção econômica de frutos em condições de salinidade dependente das práticas culturais adequadas e, também da habilidade das plantas em reagir aos efeitos salinos. Porém, a redução na produção de massa seca e na produtividade total e comercial em tomate com o aumento da salinidade tem sido reportada por diversos autores, tanto em solo (CAMPOS AL-BUSAIDI et al., 2009; et al., 2006; MAGAN et al., 2008; MALASH et al., 2002; YURTSEVEN et al., 2005) como em cultivo hidropônico (AL-ERYANI, 2004; MAGGIO et al., 2007).

$\mathrm{O}$ presente trabalho objetivou avaliar $\mathrm{O}$ crescimento, consumo hídrico e a produção de tomate cereja em sistema hidropônico com fibra de coco utilizando rejeito da dessalinização da água de uma estação de tratamento em Mossoró, RN.

\section{Material e métodos}

O experimento foi realizado, no período de março a junho de 2008, em um ambiente protegido do Departamento de Ciências Ambientais e Tecnológicas da Universidade Federal Rural do Semi-Árido, localizado em Mossoró, RN (5'11' S, 37²0’ W e $18 \mathrm{~m}$ ).

$\mathrm{O}$ experimento foi conduzido em vasos de $12 \mathrm{~L}$ preenchidos com $8 \mathrm{~kg}$ de fibra de coco que serviram de sustentação para as plantas. Em cada vaso foram feitas perfurações na base e adicionada uma camada de $3 \mathrm{~cm}$ de brita coberta com manta geotêxtil (bidim) para permitir a drenagem do excesso de água aplicada nas irrigações.

A solução nutritiva básica tinha a seguinte constituição conforme recomendação de Santos (2002), sendo dissolvidos, por cada $100 \mathrm{~L}$ de água, $805 \mathrm{~g}$ nitrato de cálcio, $334 \mathrm{~g}$ nitrato de potássio, $175 \mathrm{~g}$ de fosfato monoamônico - MAP, $252 \mathrm{~g}$ sulfato de magnésio e $10 \mathrm{~g}$ de Quelatec ${ }^{\circledR}$ (mistura sólida de EDTA-chelated nutrientes contendo $0.28 \% \mathrm{Cu}, 7.5 \% \mathrm{Fe}, 3.5 \% \mathrm{Mn}, 0.7 \% \mathrm{Zn}, 0.65 \%$ B e $0.3 \% \mathrm{Mo})$.

As mudas de tomate cereja (Lycopersicon esculentum L., cv. Samambaia) foram transplantadas para os vasos aos 15 dias após a semeadura; cada vaso recebeu apenas uma muda e foram dispostos de modo a proporcionar um espaçamento de 1 x $0,5 \mathrm{~m}$ entre plantas. Foram instalados mourões nas extremidades de 
cada fileira para amarração de três fios de arame para tutoramento das plantas. A condução da cultura foi feita em espaldeiras verticais de $2 \mathrm{~m}$ de altura e com auxílio de fita de ráfia, eliminando-se os excessos de brotações laterais por meio de podas manuais (FIG. 1). À medida que as plantas se desenvolviam foram sendo eliminadas algumas hastes e as folhas velhas da parte basal, para melhorar a luminosidade e ventilação.

$\mathrm{O}$ delineamento experimental foi inteiramente casualizado, com quatro repetições e cinco tratamentos, obtidos pelo acréscimo de rejeito da dessalinização da água salobra na solução nutritiva elaborada, que correspondeu a valores de condutividade elétrica da solução $\left(\mathrm{CE}_{\mathrm{s}}\right) \mathrm{de}$ $2,1 \mathrm{dS} \mathrm{m}^{-1}$ (sem a adição de rejeito salino), 3,55 dS m${ }^{-1}$ (25\% de rejeito salino), $4,88 \mathrm{dS} \mathrm{m}^{-1}$ (50\% de rejeito salino), $6,02 \mathrm{dS} \mathrm{m}^{-1}$ (75\% de rejeito salino) e $6,96 \mathrm{dS} \mathrm{m}^{-1}(100 \%$ de rejeito salino). O rejeito da dessalinização da água foi coletado de uma unidade de tratamento de água salobra em uma comunidade rural localizada em Mossoró-RN, enquanto que a água de abastecimento $\left(\mathrm{CEa}=0,52 \mathrm{dS} \mathrm{m}^{-1}\right)$ foi proveniente do campus da UFERSA.

A solução nutritiva foi fornecida diariamente na água de irrigação, sendo o volume de solução suficiente para preencher o substrato na capacidade máxima de retenção, calculado a partir de tensiômetros instalados a $20 \mathrm{~cm}$ de profundidade e da curva característica de retenção de água da fibra de coco nos vasos, construída previamente.

Para cada nível de salinidade, a solução nutritiva foi armazenada em tanque independente de $500 \mathrm{~L}$, sendo a solução nutritiva renovada a cada 15 dias. A CE da solução e o pH foram medidos a cada 2 dias na irrigação e a lixiviação da solução não excedeu $5 \%$ do volume aplicado. $\mathrm{O} \mathrm{pH}$ médio ao longo do ciclo do experimento variou de 6,0 a 6,5 em todos os tratamentos.

Semanalmente, realizavam-se medidas da altura das plantas, medindo-se a distância entre a superfície do solo e a gema apical, do diâmetro da haste, tomandose como referência a região da haste localizada a $1 \mathrm{~cm}$ de altura em relação à superfície do solo, e do consumo hídrico, que foi estimado através das leituras do tensiômetro instalado a $20 \mathrm{~cm}$ de profundidade, utilizando uma curva característica do substrato estimada por meio de regressão exponencial simples.

Os frutos foram colhidos a partir dos 120 dias após o transplantio (DAT) quando completavam a maturação. Os frutos com podridão apical foram considerados como não comercial. O peso fresco dos frutos, comercial e não comercial, foram registrados individualmente. Ao final da colheita (127 DAT), foram coletadas as plantas de cada tratamento para determinação da área foliar (AF), utilizando o integrador de área foliar (Licor, LI-3100) e da matéria seca da parte aérea, após secagem em estufa com circulação forçada de ar a $70^{\circ} \mathrm{C}$.

Os dados foram submetidos às análises de variância e de regressão utilizando-se o software SISVAR (FERREIRA, 2000).

\section{Resultados e discussão}

O diâmetro do colo e altura da haste do tomateiro ajustaram-se significativamente $(\mathrm{p}<0,05)$ ao modelos quadrático e linear respectivamente (FIG. 2). No entanto, não se constatou diferença significativa entre os níveis de salinidade ao longo do ciclo da cultura. A
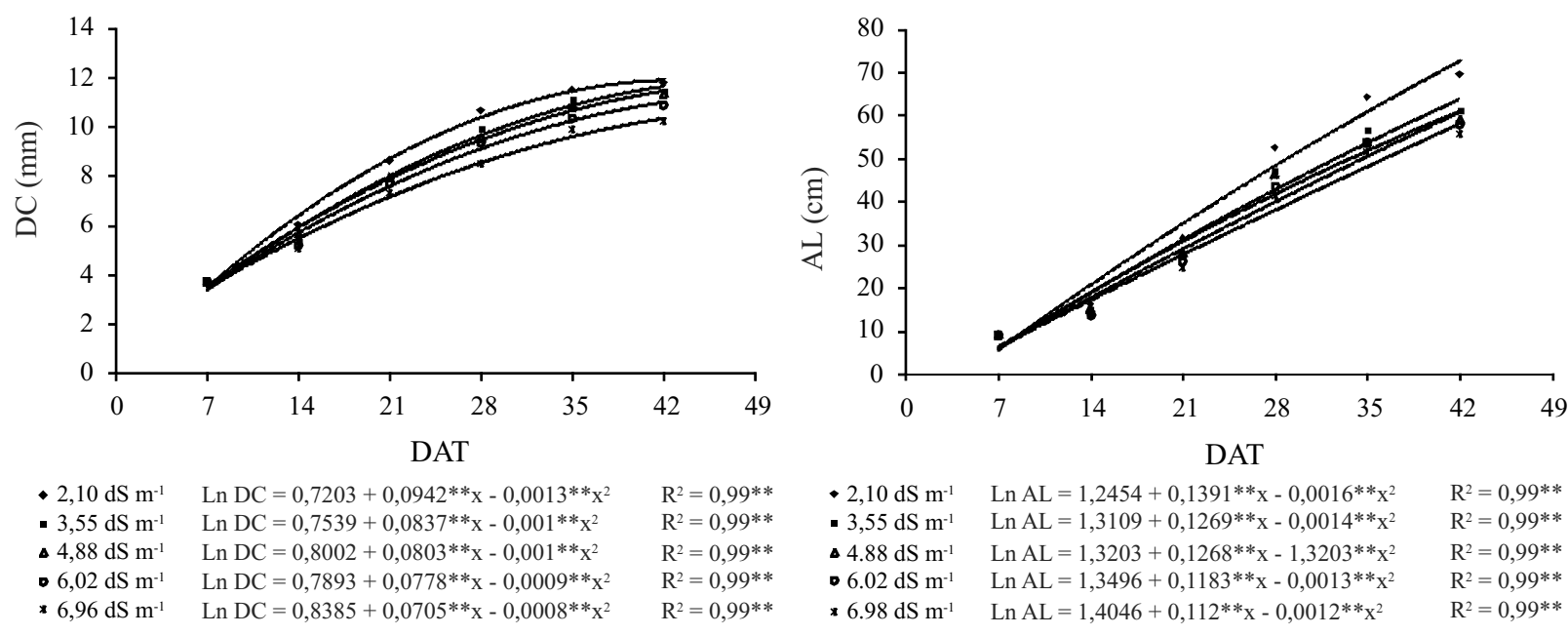

Figura 1 - Condução e espaçamento da cultura (A) e tutoramento com fitas de ráfia (B) 


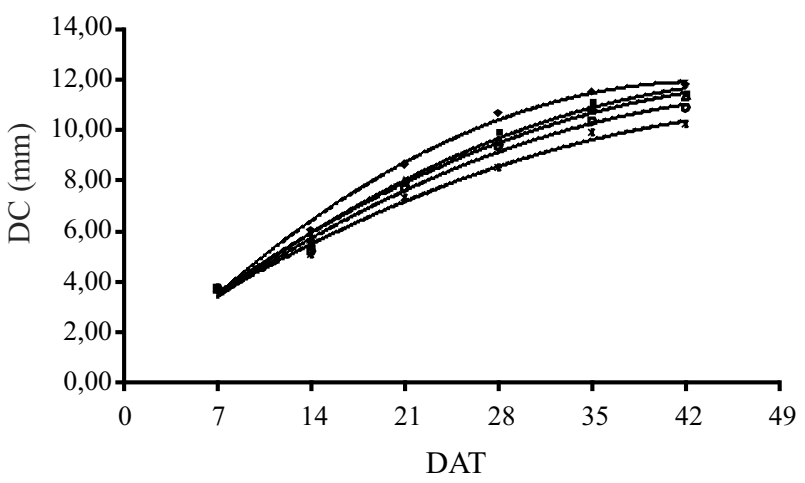

- $2,10 \mathrm{dS} \mathrm{m}^{-1} \quad$ Ln DC $=0,7203+0,0942 * * \mathrm{x}-0,0013 * * \mathrm{x}^{2}$

- 3,55 $\mathrm{dS} \mathrm{m}^{-1} \quad$ Ln DC $=0,7539+0,0837 * * \mathrm{x}-0,001 * * \mathrm{x}^{2}$

$\Delta 4,88 \mathrm{dS} \mathrm{m}^{-1} \quad \operatorname{Ln} \mathrm{DC}=0,8002+0,0803 * * \mathrm{x}-0,001 * * \mathrm{x}^{2}$

- $6,02 \mathrm{dS} \mathrm{m}^{-1} \quad$ Ln DC $=0,7893+0,0778 * * \mathrm{x}-0,0009 * * \mathrm{x}^{2}$

* $6,96 \mathrm{dS} \mathrm{m}^{-1} \quad$ Ln DC $=0,8385+0,0705^{* *} \mathrm{x}-0,0008^{* *} \mathrm{x}^{2}$

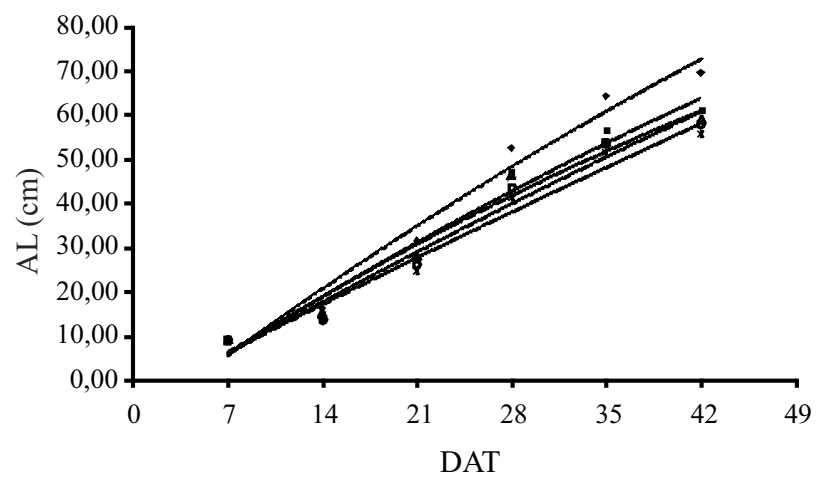

- $2,10 \mathrm{dS} \mathrm{m}^{-1} \quad \operatorname{Ln} \mathrm{AL}=1,2454+0,1391 * * \mathrm{x}-0,0016^{* *} \mathrm{x}^{2} \quad \mathrm{R}^{2}=0,99 * *$

- 3,55 dS m $\mathrm{d}^{-1} \quad \mathrm{Ln} \mathrm{AL}=1,3109+0,1269^{* *} \mathrm{x}-0,0014 * * \mathrm{x}^{2} \quad \mathrm{R}^{2}=0,99 * *$

$\Delta 4.88 \mathrm{dS} \mathrm{m}^{-1} \quad \mathrm{Ln} \mathrm{AL}=1,3203+0,1268 * * \mathrm{x}-1,3203 * * \mathrm{x}^{2} \quad \mathrm{R}^{2}=0,99 * *$

- $6.02 \mathrm{dS} \mathrm{m}^{-1} \quad \mathrm{Ln} \mathrm{AL}=1,3496+0,1183 * * \mathrm{x}-0,0013 * * \mathrm{x}^{2} \quad \mathrm{R}^{2}=0,99 * *$

$\begin{array}{lll}* 6.98 \mathrm{dS} \mathrm{m}^{-1} & \mathrm{Ln} \mathrm{AL}=1,4046+0,112 * * \mathrm{x}-0,0012 * * \mathrm{x}^{2} & \mathrm{R}^{2}=0,99 * *\end{array}$

Figura 2 - Diâmetro do colo (A) e altura da haste (B) de plantas de tomate cereja, cv. 'Samambaia', ao longo do ciclo de cultivo, para cada nível de salinidade da solução nutritiva (CEs)

altura final das plantas reduziu em média de $70 \mathrm{~cm}$ no nível 2,10 $\mathrm{dS} \mathrm{m}^{-1}$, caracterizada como testemunha, para $55 \mathrm{~cm}$ no nível $6,96 \mathrm{dS} \mathrm{m}^{-1}$, representando uma redução de $21 \%$. Já para o diâmetro da haste esta redução foi de $14 \%$. Egídio Neto (1985) constatou a diminuição do diâmetro caulinar causado pela salinidade na cultura no tomate para a indústria. Assim como, reduções na altura e no diâmetro da haste do tomateiro com o aumento da salinidade foram também observadas por Oliveira et al. (2007) e Najla et al. (2007).

Observou-se efeito linear decrescente no consumo hídrico do tomate cereja $(\mathrm{p}<0,01)$ com o aumento da salinidade da solução nutritiva preparada com rejeito salino (FIG. 3B). As reduções no consumo hídrico médio durante o ciclo, em relação ao tratamento testemunha $\left(\mathrm{T}_{0}\right)$ foram de 4,$59 ; 15,82 ; 23,58 ; 28,72 \%\left(\mathrm{~T}_{1}, \mathrm{~T}_{2}, \mathrm{~T}_{3}\right.$ e $\mathrm{T}_{4}$, respectivamente).

É possível observar na Figura 3 que à medida que o nível salino aumentou, as plantas reduziram o consumo hídrico por mecanismos fisiológicos, induzidos pela situação de estresse salino, que sacrificam fases de crescimento e desenvolvimento, reduzindo as perdas de água por transpiração. Outrossim, as plantas tendem a fechar os estômatos para reduzir as perdas de água por transpiração, resultando em uma menor taxa fotossintética, e contribuindo para redução do crescimento das espécies sob tal estresse (NOBRE, 2002). Deste modo a redução do ciclo, nesta situação de estresse, compromete os índices de crescimento
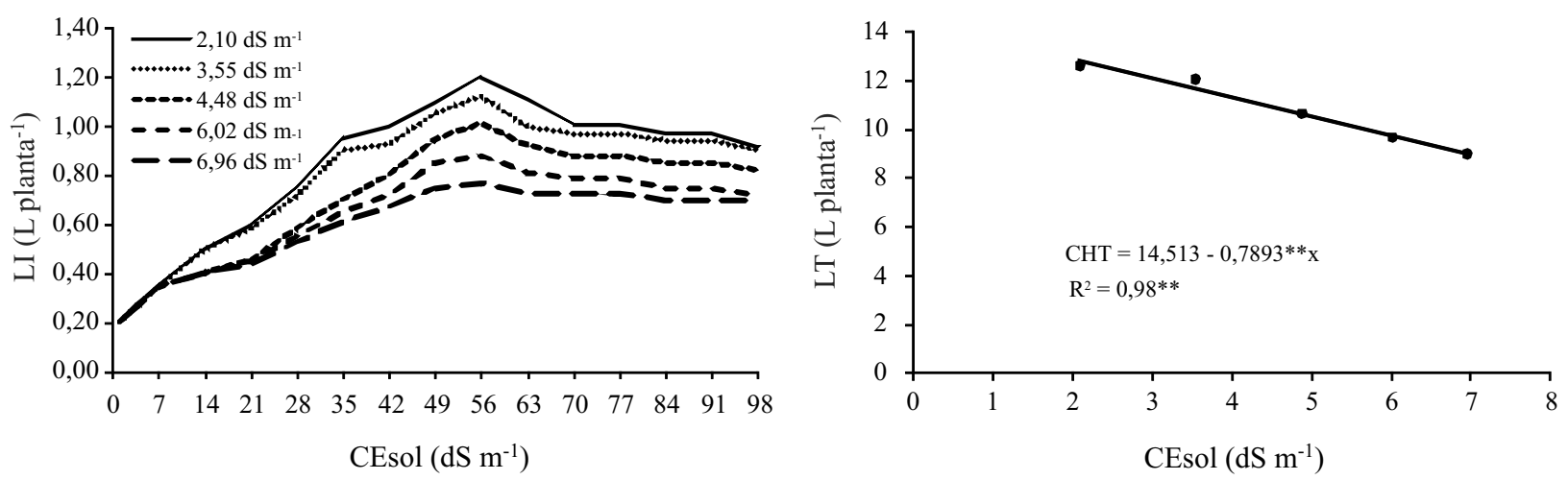

Figura 3 - Consumo hídrico, durante o ciclo, em função dos dias após o transplantio do tomate cereja (A) e consumo hídrico total em função da salinidade da solução nutritiva com a adição de rejeito salino (B) 
(FIG. 4E e 4F) e produção (FIG. 4A e 4B) devido à redução da disponibilidade de água a ser consumida, afetando a divisão e o alongamento das células (VALE et al., 2005).

Relacionando o consumo hídrico da cultura do tomate cereja ao longo do ciclo (FIG. 3A), é notório o crescimento desse consumo paralelamente ao desenvolvimento vegetativo que ocorreu até meados de
42 à 49 dias após o transplantio (DAT) para a maioria dos níveis de salinidade da solução nutritiva. Em seguida a esse período o consumo hídrico das plantas ficou estabilizado até o início das colheitas aos 90 dias. Estes dados evidenciam que o período de maior consumo de água pelas plantas, independentemente da concentração salina da solução nutritiva, é o período de desenvolvimento vegetativo e florescimento.
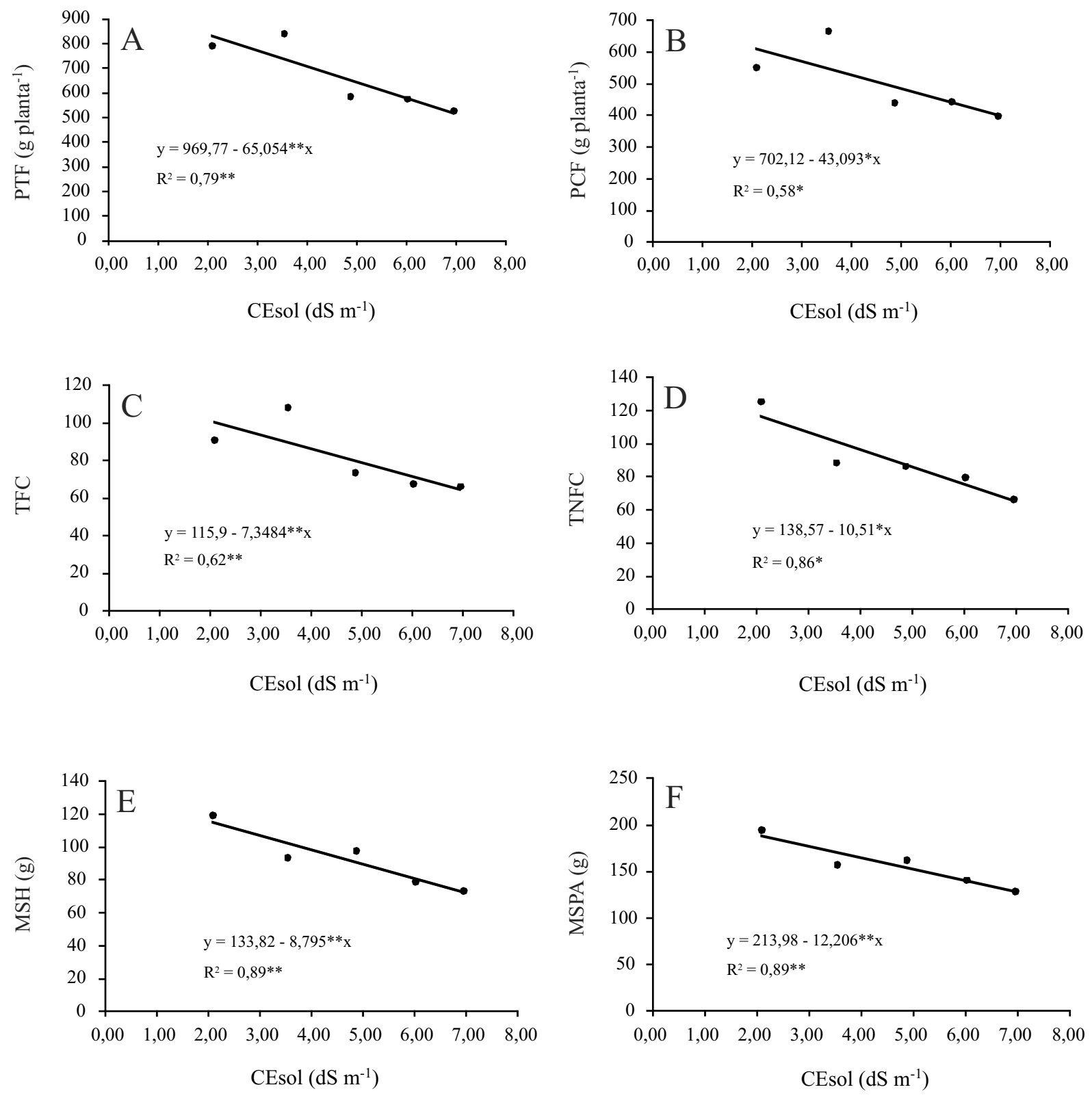

Figura 4 - Produção total de frutos (A), produção de frutos comerciais (B), total de frutos comerciais (C), não comerciais (D), massa seca da haste (E) e matéria seca da parte aérea (F) de plantas de tomate, cv. 'Samambaia', ao final do ciclo de cultivo, em função da condutividade elétrica da solução nutritiva (CEsol) 
A literatura tem demonstrado que o estresse salino reduz o crescimento e o desenvolvimento das plantas em diferentes fases físiológicas; esta redução pode estar relacionada com os efeitos adversos do excesso de sais sob homeostase iônica, balanço hídrico, nutrição mineral e metabolismo de carbono fotossintético (ZHU, 2002; MUNNS; JAMES, 2003). Contudo, os mecanismos pelos quais o estresse salino deprecia as plantas ainda é uma questão discutida devido à natureza muito complexa do estresse salino na planta.

A condutividade elétrica da solução nutritiva também reduziu a massa seca da haste (MSH) e total (MSPA) das plantas, sendo os decréscimos de MSH e MSPA de 9,14 g e 12,58 g por planta, respectivamente, para cada unidade de aumento da CEs acima de $2,1 \mathrm{dS} \mathrm{m}^{-1}$ (FIG. 4E e 4F). Os resultados obtidos estão compatíveis com Egídio Neto (1985) o qual constatou que a elevada concentração de $\mathrm{NaCl}$ na solução nutritiva promoveu redução significativa na produção da matéria seca da cultura do tomate industrial.

A produtividade total de frutos (PTF) diminuiu de 791 g por planta, no tratamento de CEs de $2,1 \mathrm{dS} \mathrm{m}^{-1}$, para $527 \mathrm{~g}$ por planta no tratamento de maior salinidade, $\mathrm{o}$ mesmo ocorreu para a produtividade de frutos comerciáveis (PFC), a qual reduziu de 552 para 398 g por planta. Ajustando-se os valores relativos de PTF e PC (PTFr e PFCr, respectivamente) ao modelo proposto por Ayers e Westcott (1999), verificando-se que as reduções de PTFr e PFCr foram de $10,9 \%$ e 9,9\%, respectivamente, para cada aumento de uma unidade de CEs, sendo a CEs limiar em torno de 3,5 $\mathrm{dS} \mathrm{m}^{-1}$ para ambas (FIG. 5). Assim, considerando-se somente a produtividade da cultura, seria possível adicionar em torno de $25 \%$ de rejeito salino à solução nutritiva sem haver perda de produção.

A redução na produção de massa seca e na produtividade total e comercial em tomate com o aumento da salinidade tem sido reportada por diversos autores, tanto em solo (AL-BUSAIDI et al., 2009; CAMPOS et al., 2006; MAGAN et al., 2008; MALASH et al., 2002) como em cultivo hidropônico (AL-ERYANI, 2004; MAGGIO et al., 2007). Sob sistema hidropônico, geralmente observa-se maior tolerância do tomateiro à salinidade do que no cultivo em solo, o que possibilita a utilização de água salina com menor risco de redução de produtividade. Além disso, águas de salinidade baixa a moderada permitem a obtenção de frutos de melhor qualidade, com maior teor de sólidos solúveis e acidez titulável (MAGAN et al, 2008), permitindo atingir mercados diferenciados.
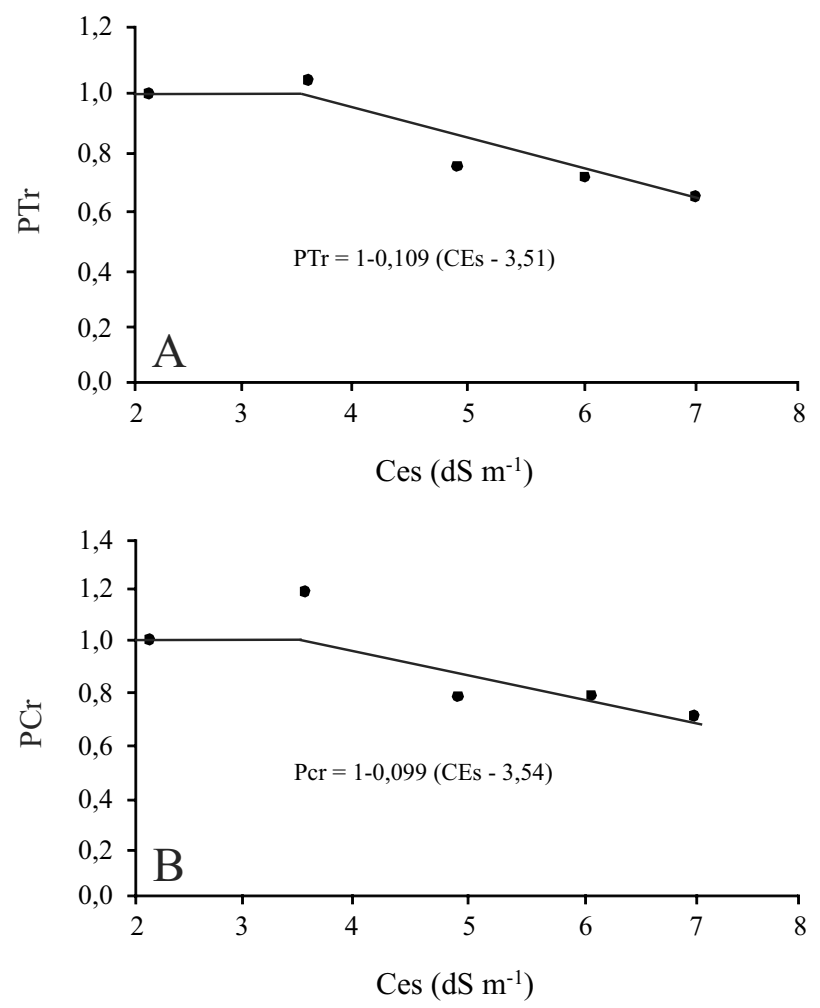

Figura 5 - Produção total (A) e comercial relativas (B) (PTr e $\mathrm{PCr}$, respectivamente) de tomate cereja, cv. 'Samambaia', em função da condutividade elétrica da solução nutritiva (CEs)

\section{Conclusões}

1. O incremento da água de rejeito salino no preparo da solução nutritiva reduz o crescimento do tomate cereja, cv. 'Samambaia' cultivado em fibra de coco em todo ciclo da cultura;

2. O consumo hídrico médio dos tratamentos foi reduzido linearmente com aumento unitário da condutividade elétrica da solução nutritiva (CEs), com decréscimo médio de $0,79 \mathrm{~L} /$ planta ao final do ciclo;

3. A adição de $25 \%$ de rejeito de dessalinizador, com CE de $3,55 \mathrm{dS} \mathrm{m}^{-1}$, à solução nutritiva permite o cultivo do tomate cereja, cv. 'Samambaia', sem haver redução na produtividade;

4. A água de rejeito da dessalinização, diluída ou não com água de abastecimento, pode ser utilizada no cultivo de tomate cereja, cv. 'Samambaia' em sistema hidropônico com reduzida perda no rendimento dos frutos, permitindo que as águas de boa qualidade, de difícil aquisição escassez, sejam utilizadas para outros fins. 


\section{Agradecimentos}

Os autores agradecem ao $\mathrm{CNPq}$ pela concessão de recursos financeiros para execução do projeto $(\mathrm{CNPq} /$ Edital Universal 2006, processo n. 486242/2006-4).

\section{Referências}

AL-BUSAIDI, A.; AL-RAWAHY, S.; AHMED, M. Response of different tomato cultivars to diluted seawater salinity. Asian Journal of Crop Science, v. 01, n. 02, p. 77-86, 2009.

AL-ERYANI, A. R. A. A. Effects of salinity on yield and postharvest quality of tomato (Lycopersicon esculentum Mill.). 2004. 140 f. Dissertação (Mestrado em Science) Serdang: Universiti Putra Malaysia, Serdang.

AYERS, R. S.; WESTCOT, D. W. A qualidade da água na agricultura. 2.ed. Campina Grande: UFPB, 1999. 153p. (Estudos FAO: Irrigação e Drenagem, 29).

CAMPOS, C. A. B. et al. Yield and fruit quality of industrial tomato under saline irrigation. Scientia Agricola, Piracicaba, v. 63 , n. 02 , p. 146-152, 2006.

EGÍDIO NETO, B. Efeito da salinidade sobre quatro cultivares de tomateiro. 1985. Dissertação (Mestrado em Ciência do solo) - Universidade Federal Rural de Pernambuco, Recife. Disponível em <http:www.ufrpe.br/química/medidio. htm>. Acesso em: 14 Jan. 2010.

FERREIRA, D. F. Manual do sistema Sisvar para análises estatísticas. Lavras: UFV, 2000, 66 p.

MAGAN, J. J. et al. Effects of salinity on fruit yield and quality of tomato grown in soil-less cultire in greenhouses in Mediterranean climatic conditions. Agricultural Water Management, Amsterdam, v. 95, n. 09, p. 1041-1055, 2008.

MAGGIO, A. et al. Salt stress response in tomato beyond the salinity tolerance threshold. Environmental and Experimental Botany, v. 59, n. 03, p. 276-282, 2007.

MALASH, N. et al. Effect of irrigation water salinity on yield and fruit quality of tomato. Acta Horticulturae, The Hague, n. 573 , p. 415-423, 2002.
MUNNS, R., JAMES, R. A. Screening methods for salinity tolerance: a case study with tetraploid wheat. Plant Soil, v. 253, n. 02, p. 201-218, 2003.

NAJLA, S. et al. Effect of salinity on tomato plant architecture. Acta Horticulturae, The Hague, n. 801, p. 1183-1190, 2007.

NOBRE, R. G. Formação de mudas enxertadas de gravioleira em condições de salinidade. 2002. 84 f. Dissertação (Mestrado em Engenharia Agrícola) - Universidade Federal de Campina Grande, Campina Grande.

OLIVEIRA, B. C. et al. Características produtivas do tomateiro submetido a diferentes níveis de sais, na água de irrigação. Revista Brasileira de Engenharia Agrícola e Ambiental, v. 11, n. 01, p. 11-16, 2007.

PORTO, E. R., AMORIM, M. C. C.; SILVA JÚNIOR, L. G. A. Uso do rejeito da dessalinização de água salobra para irrigação da erva-sal(Atriplexnummularia). Revista Brasileira de Engenharia Agrícola e Ambiental, v. 05, n. 01, p. 111-114, 2001.

RILEY, J. J.; FITZSIMMONS, K. M.; GLENN, E. P. Halophyte irrigation: an overlooked strategy for management of membrane fraction concentrate. Desalination, v. 110, n. 03, p. 197-211. 1997.

SANTOS, R. N. C. Avaliação da relação K:N e híbridos de melão em cultivo hidropônico. 2002. 98 f. Dissertação (Mestrado em Agronomia) - Escola Superior de Agricultura Luís de Quieroz/Universidade de São Paulo, Piracicaba

SOARES, T. M. et al. Destinação de águas residuárias provenientes do processo de dessalinização por osmose reversa. Revista Brasileira de Engenharia Agrícola e Ambiental, Campina Grande, v. 10, n. 03, p. 730-737, 2006.

VALE, L. S. et al. A. Efeito da salinidade na cultura do algodoeiro herbáceo. In: CONGRESO BRASILEIRO DE ALGODÃO, 5. 2005, Paraíba. Anais eletrônicos... Paraíba: EMBRAPA, 2005.

YURTSEVEN, E.; KESMEZ, G. D.; ÜNLÜKARA, A. The effects of water salinity and potassium levels on yield, fruit quality and water consumption of a native central anatolian tomato species (Lycopersicon esculentum). Agricultural Water Management, Amsterdam, v. 78, n. 01/02, p. 128-135, 2005.

ZHU, J. K. Salt and drought stress signal transduction in plants. Ann. Rev. Plant Biol., v. 53, p. 247-273, 2002. 